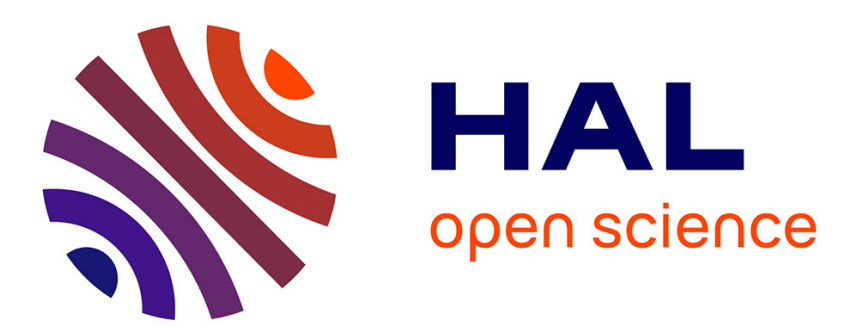

\title{
Information Ecology as a Framework for South-South Cooperation: Case Studies of Rwanda and Bangladesh ICT-Based Health Applications
}

Suzana Brown, Faheem Hussain

\section{- To cite this version:}

Suzana Brown, Faheem Hussain. Information Ecology as a Framework for South-South Cooperation: Case Studies of Rwanda and Bangladesh ICT-Based Health Applications. 14th International Conference on Social Implications of Computers in Developing Countries (ICT4D), May 2017, Yogyakarta, Indonesia. pp.803-808, 10.1007/978-3-319-59111-7_65 . hal-01650068

\section{HAL Id: hal-01650068 \\ https://hal.inria.fr/hal-01650068}

Submitted on 28 Nov 2017

HAL is a multi-disciplinary open access archive for the deposit and dissemination of scientific research documents, whether they are published or not. The documents may come from teaching and research institutions in France or abroad, or from public or private research centers.
L'archive ouverte pluridisciplinaire HAL, est destinée au dépôt et à la diffusion de documents scientifiques de niveau recherche, publiés ou non, émanant des établissements d'enseignement et de recherche français ou étrangers, des laboratoires publics ou privés.

\section{(c)(1)}

Distributed under a Creative Commons Attribution| 4.0 International License 


\title{
Information Ecology as a Framework for South-South Cooperation: Case Studies of Rwanda and Bangladesh ICT-based Health Applications
}

\author{
Suzana Brown (0000-0002-2184-1701), Faheem Hussain (0000-0003-4173-3094) \\ Department of Technology and Society, SUNY Korea, 119 Songdo, Incheon, Korea, \\ 21985. \\ suzana.brown@sunykorea.ac.kr, faheem.hussain@stonybrook.edu
}

\begin{abstract}
Information Ecology represents a system of people, values, and technologies in a specific local environment. What makes Information Ecology different is that the spotlight is not on the technology but on human activities that are served by technology. As such it could be a powerful lens for understanding, evaluating, and eventually guiding South-South cooperation. We use Information Ecology to critically analyze two ICT-infused community health services, one in Bangladesh and one in Rwanda; and propose improvements for each case. Based on that analysis we believe that this framework can facilitate theoretical basis for guiding South-South cooperation, transferring knowledge and technology, and implementing policy recommendations.
\end{abstract}

Keywords: South-South cooperation, framework, community health

\section{Introduction}

In this note, we argue that Information Ecology is a powerful lens for understanding, evaluating, and guiding South-South cooperation. Information Ecology borrows its concept from biology with its complex dynamic interactions, diverse species and coevolution of the system. Information Ecology's main contribution is that the role of technology should not be isolated but interpreted as a part of the system [1].

South-South cooperation is led by the developing countries with positive signs of development. Countries like India, Brazil, and China are the leaders in disseminating their expertise and building new types of relationship with the other emerging countries, the relationship of exchange and economic cooperation. We analyze Rwanda and Bangladesh because of their prominent place in the emerging economies of Africa and South Asia. In addition, both countries have identified ICT as an enabler for coming out of poverty, so we critically analyze two specific ICT-infused community health services, using Information Ecology. Valuable field research experience in the above countries is allowing us firsthand knowledge about local and regional conditions. 


\section{Related work}

South-South collaboration is a new area of research, with studies on scientific and technical collaborations [2], as well as economic and social collaboration [3]. However, with no studies on collaboration and sharing in community healthcare design. In addition, comparing lessons from development projects from multiple countries, has always been a struggle mostly because there is no common framework. In attempt to bridge that gap, we turn to Information Ecology. Information Ecology is a new concept in ICT for development but already used as a theoretical framework to explore technology-focused initiatives that attempt to narrow the digital divide in education [4], and disaster management [5]. To our knowledge, Information Ecology had not been applied to the knowledge transfer in the health field.

Rwanda bases its health system on Community Health Workers (CHWs) who connect population to a scarce medical personal. CHWs, frequently the backbone of preventative and curative care [6], often work as volunteers. A review of literature [7] on CHWs and mobile technology finds that CHWs have used mobile tools for maternal and child health, HIV/AIDS, and reproductive health. CHWs often use mobile technology to collect field based health data, receive alerts and reminders, and facilitate health education sessions.

In Bangladesh, there is a multitude of electronic health applications [8] but we focus on Info Ladies because of their unique position as entrepreneurs who connect population to electronic health and other information. Despite the rapid popularity of mobile phone, researchers identified the need for a human interface alongside the last mile of ICT solutions for information access in Bangladesh. A local NGO, D.Net, explored this synergy between mobile telephony and local women, and establish the Info Lady network [9].

\section{Information ecology as a framework}

Information Ecology represents a complex ecosystem of parts and relationships [1]. It is a system of people, values, and technologies in a specific local environment. What makes information ecology different is that the spotlight is not on technology itself but on human activities that are served by technology [1]. The ecosystem exhibits diversity and continual evolution. Different parts of ecology coevolve, changing together their relationships in the system. Several keystone species are necessary for the survival of the ecosystem. Finally, information ecologies have a sense of locality. Next, we apply Information Ecology lens to analyze two community health case studies.

\section{$4 \quad$ Bangladesh case description}

Bangladesh has come a long way from its struggling past, the country's economy is growing fast, predicted to be among the 25 largest economies by 2050 . In addition, 
Bangladesh has performed well in education, women empowerment, and other social development benchmarks [10]. Within Bangladesh, community-based health programs play a major role in the national health sector [11]. We have chosen the "Info Lady" program of D.Net for our analysis. The primary reason behind this selection is its significant positive impact in rural Bangladesh. Info Lady program is a synergy between mobile telephony and local women for providing information services. Info Ladies primarily provide services in Health and Agriculture [12]. Currently, there are 50 Info Ladies, providing their services in 300 villages of Bangladesh. On average, an Info Lady earns around \$100, a significant amount for working women in Bangladesh. The initial setup cost of an Info Lady is around \$600, which includes a laptop and a bicycle. Women interested in becoming Info Ladies can buy the necessary equipment from the D.Net supply stores [12].

\section{Information ecology analysis}

System. The government initiative "Digital Bangladesh" was critical for the system creation in Bangladesh. It allowed D.Net to roll out the Info Lady program to reach the underserved communities with health and other information services. The other major element of Bangladesh's ecosystem in community-based health service are the infomediaries or Info Ladies, who have multiple roles, as a source of critical health information and an interface between the government/NGOs and the general population in participatory design.

Diversity. As a community-based organization, D.Net offers support service on agriculture and women health care. Info Ladies focus on support for pregnant women, livelihood information for farmers, information services for youth, health checkups for rural people, and ICT-enabled life skills.

Coevolution. Infomediaries introduced ICT-enabled services in communities where there was a scarcity of useful information. Such introductions resulted in more access to ICTs and more communication with the rest of world. Cheaper and more convenient information access meant new needs, thus pushing the Info Lady initiative to new terrains professional development.

Keystone species. Info Ladies, as infomediaries, are the most critical group of keystone species. Their customers have been satisfied with the effective use communication technologies to address their problems. Another important species is the supporting organization, D.Net. This organization's focus on the underserved communities in Bangladesh helped immensely in designing and managing the Info Lady initiative [12].

Locality. The Info Lady project by design is a hybrid solution, where the socially acceptable human factor is providing the information to women using ICTs. The physical access challenge is being addressed with the use of bicycles (by infomediaries) and digital proximity of expert consultants from D.Net. Such localization of service meant better acceptability of Info Lady project within the communities it's serving, ensuring further collaboration. 


\section{Rwanda case description}

Since its genocide in 1994 Rwandan economic growth has been impressive 8\% per year [13]. Strong economic growth was accompanied by substantial drop in child mortality [13]. In the health sector, Rwanda has been leveraging ICT technology to improve access to healthcare. However, the country still faces the most severe shortages of human resources for health on the continent. In response to these health burdens, Rwanda introduced CHWs as major participants in the Rwandan health system. Rwanda implemented one e-health initiative based on open source software, RapidSMS, which allows CHWs to follow mother-infant pair [14]. However, it is used only for emergency cases. We have chosen a different case study which requires a system in which CHWs are infomediaries. The study tested a hypothesis that Rwandan CHWs could use smartphones for health data collection to monitor children's growth. This study demonstrated that using electronic tools for health data collection allows better tracking of health indicators [15].

\section{Information ecology analysis}

System. Rwandan $\mathrm{MoH}$ is the leader of community health system with little involvement of NGOs. CHWs only visit population and collect information. The following groups are part of the ecosystem: mobile service operators provide connectivity; software engineers design and maintain EHR system.

Diversity. Rwanda is missing many actors of community health system. CHWs do not give feedbacks about the issues regarding implementation, and NGOs are on the fringes of the system collecting their own health data.

Coevolution. Coevolution involves generating new ideas, tools, or activities. In Rwanda, it requires a transformation on two levels: 1) from aggregate paper tracking to individual tracking of health indicators; and 2) from emergency case responses to a long term electronic health data collection.

Keystone species. CHWs are mediators, common for a keystone species. $\mathrm{MoH}$ is not compensating CHWs for their service. Instead, it contributes to their cooperatives, and it encourages them to start a small business. However, there is no synergy in such approach. $\mathrm{MoH}$ should find a better motivation tool to ensure the survival of CHWs as a keystone species.

Locality. One Rwandan challenge is inadequate ICT literacy. Ministry of Youth and ICT reports only $3.3 \%$ of the population has adequate ICT literacy. Opportunities in Rwanda are: high penetration of cellular network and the extensive network of CHWs already trained to collect basic health indicators.

\section{Discussion}

Information Ecology framework allows us to analyze the two cases using same parameters. Based on this comparative analysis, we found out that major changes are needed in the domains of Diversify, Coevolution, and Keystone Species. Comparing systems between Rwandan and Bangladesh we observe several key differences. Bangladesh has a better diversity of services in comparison to Rwanda where CHWs 
are limiting their role to data collection. In addition, Rwandan system does not include CHWs in the system design, which hampers coevolution of the ecosystem. Bangladesh has a better community participation, with the role of different systems well defined.

Keystone species are clear in both cases. However, one main difference is that Info Ladies are entrepreneurs who provide information services. As volunteers Rwandan CHWs are less motived to ensure system survival, finding a proper motivation for their survival should be a priority for Rwanda. Local obstacles also differ, the main local problem in Rwanda is ICT literacy. In Bangladesh, the proliferation of mobile devices and cheap network connections has enabled population to have access to basic information, so Info Ladies must evolve and be innovative about their services.

\section{Conclusions}

Comparative research using Information Ecology framework allow us to propose the following recommendations for improving ICT-based health services in Rwanda and Bangladesh: improve support for keystone species to improve their engagement and motivation, and ensure the survival of the system; increase diversity in the ecosystem by offering a variety of services and involving diverse providers; invite community participation in the system design to improve coevolution. Enabling experience transfer and guiding South-South cooperation the research community requires a common framework. We believe this framework can facilitate strong theoretical basis for guiding South-South cooperation and transferring knowledge.

\section{Acknowledgment}

This research was supported by the MSIP (Ministry of Science, ICT and Future Planning), Korea, under the "ICT Consilience Creative Program" (IITP-2015-R034615-1007) supervised by the IITP (Institute for Information \& communications Technology Promotion).

\section{References}

1. Nardi, B. and V. O’Day, "Information ecologies", Reference \& User Services Quarterly, 1998. 38(1): p. 49-58.

2. Centellas, K. "Cameroon is Just like Bolivia: Southern Expertise and the Construction of Equivalency in South-South Scientific Collaborations", Information\& Culture, vol. 49. No. 2, 2014, University of Texas Press, doi: 10.'7560/IC49203.

3. Izuchukw, O., Ofori, D., "Why South-South FDI is Booming: Case Study of China FDI in Nigeria", Journal of Asian Economic and Financial Review, 2014, vol. 4, issue 3, pp. 361376. 
4. Thapa, D., Sein, M., "Information Ecology as a holistic lens to understand ICTD initiatives: A case study of OLPC deployment in Nepal”, Proceedings of ICTD '16, June 03-06, 2016, Ann Arbor, MI, USA, doi:10.1145/2909609.2909610

5. Sakurai, M, Thapa, D., "Exploring Effective Ecosystems in Disaster Management: Case studies of Japan and Nepal", Hawaii International Conference on System Sciences, Jan. 47, 2017.

6. Hermann, K., et al., 2009, "Community health workers for ART in sub-Saharan Africa: learning from experience - capitalizing on new opportunities", Human Resources for Health, 2009, vol. 7, no. 31, doi: 10.1186/1478-4491-7-3

7. Braun R, Catalani C, Wimbush J, Israelski D, 2013, "Community Health Workers and Mobile Technology: A Systematic Review of the Literature”, PLoS ONE 8(6): e65772. doi:10.1371/journal.pone.0065772

8. Arifeen, Christou, Reichenbach, Arfina, Azad, Islam, Peters, "Community-based approaches and partnerships: innovations in health-service delivery in Bangladesh", Lancet 2013; 382: 2012-26.

9. Dnet web site, http://dnet.org.bd/page/Gneric/0/61/145/85\#sthash.qleLVYOK.dpuf

10. Arifeen, S., Christou, A., Reichenbach, L., Arfina F., Osman, K. Azad, K. Islam, F. Ahmed, HB Perry, DH Peters, "Community-based approaches and partnerships: innovations in health-service delivery in Bangladesh", Lancet 2013; 382: 2012-26.

11. Raihan, Uddin, Adib, "Moni, the Mobile Lady: an Initiative of D.Net Bangladesh", A Quarterly of the Commonwealth Education Media Centre for Asia, vol. 12, no. 3, March 2007.

12. "Bangladeshi traveling Infoladies: a rural revolution", Jan 2015, Philanthropy Age, http://www.philanthropyage.org/2015/01/25/bangladeshs-travelling-infoladies-ruralrevolution/

13. "Rwanda Economic Outlook", African Development Bank, African Economic Outlook 2015, http://www.afdb.org/en/countries/east-africa/rwanda/rwanda-economic-outlook/

14. Ngabo, Nguimfack, Nwaigwe, "Designing and Implementing an Innovative SMS-based alert system (RapidSMS-MCH) to monitor pregnancy and reduce maternal and child deaths in Rwanda", The Pan African Medical Journal. 2012, vol. 13, pp.13:31.

15. Brown, S., McSharry, P., "Improving accuracy and usability of growth charts: Case study of Rwanda", British Medical Journal (BMJ Open),2016, vol. 6, issue 1, e009046, doi:10.1136/bmjopen-2015-009046. 